\title{
Failure Mechanisms and the Control of a Longwall Face with a Large Mining Height within a Shallow-Buried Coal Seam
}

\author{
Haijun Wang $\mathbb{D},{ }^{1,2}$ Yingjie Liu $\mathbb{D},{ }^{3}$ Yuesong Tang $\mathbb{D}^{1},{ }^{1}$ Hao Gong, ${ }^{1}$ and Guoliang Xu $\mathbb{D}^{1}$ \\ ${ }^{1}$ School of Energy and Mining Engineering, China University of Mining and Technology-Beijing, Beijing 100083, China \\ ${ }^{2} X i$ 'an Research Institute of CCTEG, Xi'an, Shanxi 710077, China \\ ${ }^{3}$ China Coal Research Institute of CCTEG, Beijing 100013, China
}

Correspondence should be addressed to Yingjie Liu; 290783585@qq.com

Received 10 May 2021; Accepted 12 August 2021; Published 24 August 2021

Academic Editor: Haiyan Wang

Copyright $\odot 2021$ Haijun Wang et al. This is an open access article distributed under the Creative Commons Attribution License, which permits unrestricted use, distribution, and reproduction in any medium, provided the original work is properly cited.

\begin{abstract}
The capabilities of mining equipment and technology in China have been improving rapidly in recent years. Correspondingly, in the western part of the country, the mining heights of longwall faces in shallow-buried coal seams have shown an increasing trend, resulting in enhanced mining efficiency. However, the problems associated with the possible failure of the coal wall then increase and remain a serious difficulty, restricting safe and efficient mining operations. In the present study, the 12401 longwall face of the Shangwan Coal Mine, Inner Mongolia, China, with a mining height of $8.8 \mathrm{~m}$, is taken as an example to study the mechanisms underlying failure phenomena of coal walls and their control methods. Our results show that the failure region inward of the longwall face is small in shallow-buried coal seams, and the damage degree of the exposed coal wall is low. The medium and higher sections of the coal wall display a dynamic failure mode, while the broken coal blocks, given their initial speed, threaten the safety of coal miners. A mechanical model was developed, from which the conditions for tensile failure and structural instability are deduced. Horizontal displacement in the lower part of the coal wall is small, where no tensile stress emerges. On the other hand, in the intermediate and higher parts of the coal wall, horizontal displacement is relatively large. In addition, tensile stress increases first with increasing distance from the floor and then decreases to zero. Experiments using physical models representing different mining heights have been carried out and showed that the horizontal displacement increases from 6 to $12 \mathrm{~mm}$ and load-bearing capacity decreases from 20 to $7.9 \mathrm{kN}$ when the coal wall increases in height from 3 to $9 \mathrm{~m}$. Furthermore, failure depth and failure height show an increasing trend. It is therefore proposed that a large initial support force, large maximum support force, large support stiffness, and large support height of a coal wall-protecting guard are required for the improved stability of high coal walls, which operate well in the Shangwan coal mine.
\end{abstract}

\section{Introduction}

There are a large number of thick coal seams in the west of China with simple geological conditions and shallow burial depths, which have produced a large coal production base of 100 million tons, as represented by the China Shendong Energy Company. There are two main mining technologies for exploiting thick coal seams: large mining height and top coal caving. The application of top coal caving depends on the coal seam strength and mining stress, while large mining height only has stricter requirements in terms of the supporting equipment for the working face $[1,2]$. At present, China has independently developed a large mining height hydraulic support system with a rated support resistance of $26000 \mathrm{kN}$ and a support height of $9 \mathrm{~m}$, which has been successfully applied in the Shendong Shangwan Coal Mine $[3,4]$. The improvements in the standards and capacity of such supporting equipment make the use of fully mechanized mining technology with large mining heights the first choice for mining coal seams with thicknesses of less than $9 \mathrm{~m}$. However, with increasing wall height and the resulting decrease in stability, coal wall slicing has become the main factor in restricting the production efficiency of such a working face.

To improve the control of coal wall stability, domestic and foreign experts and researchers have conducted a large 
number of studies on coal wall failure characteristics, failure mechanisms, and control methods $[5,6]$. Through field measurements, it has been found that there are several forms of upper lamping, lower lamping, middle lamping, and whole lamping on the coal wall of fully mechanized mining faces with high $(>7 \mathrm{~m})$ mining heights, of which the stress concentration caused by roof subsidence makes the upper lamping the most common [7, 8]. Through the use of physical simulation experiments, several factors have been examined. These include the damage form, the effect of the dip angle of the coal wall face, the angle of mined-out areas, uneven backfilling and filling period of three parts, and the nonuniform distribution of mining stress along the direction of the working face, which puts forward an extrusion to the slip and shear slip of two kinds of coal wall damage form [9-11].

Indoor mechanical experiments have found that the cohesion of coal increases with increasing water content, and measures were proposed to increase the stability of the coal wall by injecting water into the coal seam. This method can also have the effect of removing dust from the working face [12-14]. Some experts and researchers believe that increasing burial depth will lead to increased mining-induced stress levels and that the coal body in front of the working face will undergo a high degree of plastic flow within a highstress environment and will enter the residual deformation stage. After exposure, a coal body with low bearing capacity may suffer structural failure under the action of roof pressure; hence, the plastic flow briquette wall lamping is proposed [15]. Numerical modeling has been used to simulate the deformation and failure characteristics of coal walls, which allowed the characteristics of the distribution of shear deformation in the concentrated zone of the coal body in front of the working face to be obtained. It was found that the shear deformation concentrated zone saw the extended trace of macroscopic cracks, and the intersection of the shear deformation concentrated zone and the exposed surface of the coal wall lead to the occurrence of coal wall lamping $[16,17]$. In the coal wall, failure mechanisms associated with shear and tensile stresses have been identified, and structural mechanics models describing these failure mechanisms have been deduced $[18,19]$. It was found that there is a coal wall before destroying large lateral deformation characteristics; based on the characteristics of the proposed trip and grouting flexible coal wall reinforcement technology, establish a "trip-serious-mechanics" model of coal. The stability conditions of reinforced coal were obtained, and optimization studies of the process parameters of flexible reinforcement have been carried out [20-22].

By analyzing the slab-side conditions of a coal wall forming an inclined mining face, the stability coefficient of a coal wall can be defined as the ratio of the ultimate bearing capacity of the coal wall to the load of the roof, allowing the influence of the inclined angle of the working face on the stability of the coal wall to be obtained $[23,24]$. The upper bound theorem is then used to analyze the ultimate bearing capacity of the coal wall failure as a function of the shear, tensile, and tension-shear failure. This leads to the concept of crack initiation angle of coal wall failure, with a formulation for determining the crack initiation angle being proposed [25-27]. In terms of coal wall stability control, grouting reinforcement of the coal wall has been put forward, and the required parameters, such as grouting hole length, angle, and diffusion characteristics of the slurry inserted into the grouting hole, have been analyzed $[28,29]$, while examining the impact of support stiffness on the stability of the coal wall. This increases the support stiffness, which can provide timely high-strength hydraulic support for the roof load. This leads to the roof load acting on the coal wall being alleviated, from which the selection method of hydraulic support based on the dual synergistic control of the roof and coal wall is proposed $[30,31]$.

Previous research has promoted various ways of controlling coal wall stability for fully mechanized mining faces. However, with the development of coal resources in the western province and the technical improvements resulting from mining equipment research and development, the height of a single cut along a large mining face keeps rising, with coal wall instability still being the main factor that restricts the safe and efficient production for this kind of working face. Based on the $8.8 \mathrm{~m}$ high working face in the Shangwan coal mine, the authors have analyzed the failure mechanisms of the mining wall under the condition of shallow burial and put forward control countermeasures that have the potential to provide a reference for the exploitation of thick coal seams with similar geological characteristics.

\section{Failure Characteristics of Coal Walls in Shallow-Buried and Large-Height Stopes}

The 12401 working face of the Shangwan coal mine is the first mining face of the panel area. The working face length is $300 \mathrm{~m}$, the strike advancing length is $5286 \mathrm{~m}$, and the burial depth is between 120 and $160 \mathrm{~m}$. It is a near-horizontal coal seam with the average thickness of the main coal seam at the working face being $8.8 \mathrm{~m}$, and the compressive strength of the coal body is $15 \mathrm{MPa}$. The shearer cutting height is between 4.3 and $8.6 \mathrm{~m}$, the hydraulic support height is between 4.0 and $8.8 \mathrm{~m}$, the initial support force of the support is $19782 \mathrm{kN}$, and the working resistance is $26000 \mathrm{kN}$. The mining technology employed has been adapted to large mining heights, and the roof is managed by the caving method. The roof strata are mainly composed of sandy mudstone and sandstone with high strength and are relatively hard. Due to the large height of the mining face, the overburden is highly disturbed, with overburden failure cracks developing to the surface. In the process of advancing the working face, both surface opening fractures and step dislocation fractures develop. Under the condition of highintensity mining, failure of the working face occurs frequently, affecting the production efficiency and endangering the miners.

The initial pressure of the working face is $45 \mathrm{~m}$, and the pressure duration is $5 \mathrm{~m}$. The initial pressure step distance of the working face is essentially the same as that of the $8 \mathrm{~m}$ working face in the same coal seam in an adjacent mine, and the average cycle pressure step distance is $12.1 \mathrm{~m}$. When the 
advance speed of the working face is slow, the pressure step distance is shorter, and when the advancement speed accelerates, the pressure step distance becomes larger. In each case, there is an obvious boundary between pressure and no pressure. When there is no pressure, it is generally not more than 300 bar.

An example of a failure of the coal wall at working face 12401 is shown in Figure 1. The fractures on the coal wall surface are highly developed, among which horizontal and longitudinal fractures are the most obvious, but the development depth of the fractures is small, and the observed open fractures are generally less than $0.5 \mathrm{~m}$ (Figures $1(\mathrm{a})$ and 1(b)). The upper part of the coal wall is seriously damaged, with the coal body losing its bearing capacity; however, it can remain stable under the action of the guard plate. The coal body falls off in the process of coal cutting, which influences production efficiency and safety. The coal shearer cutting affected zone in the central and upper wall shows dynamic failure phenomena, where the face direction advances about 20 to $30 \mathrm{~m}$ within the scope of the coal shearer advancing at a higher speed into the coal wall, using a large split ring. Due to the destruction of the coal, the initial startup speed is high, leading to significant threats to production safety. To prevent the broken coal from falling into the internal stent and harming the production staff, barbed wire is used on the outside of the support column, as shown in Figure 1(c).

\section{Failure Mechanisms of the High Wall of a Shallow Coal Seam}

3.1. Simplified Mechanical Model of Coal Wall. The nature of the rock structure surrounding an area of high coal wall mining is shown in Figure 2(a). Immediate roof increases with the increasing mining risk, main roof can form balanced structure, bearing capacity reduced gangue, the yield gravity of goaf roof rock transformed the entity in front of mining face, and the formation of abutment pressure leaded to the development and destruction of mining-induced fractures in mining wall, resulting in the formation of broken zone (gray area in Figure 2) in front of mining face, and the broken zone was a complete zone (black area in Figure 2). The maximum buried depth of the mining area is $160 \mathrm{~m}$, and the maximum deadweight stress of the overburden is about $4 \mathrm{MPa}$, without considering background tectonic stresses. According to previous studies [32-35], the maximum abetment pressure concentration coefficient in front of the working face can reach 4 , from which the peak abetment pressure is determined to be $16 \mathrm{MPa}$, which is equivalent to the uniaxial compressive strength of a coal body. Therefore, the coal wall failure fracture development depth of the 12401 working face is low, and the width of the fracture zone in front of the working face is small. A large number of measurements furthermore show that the range of the depth of damaged coal in front of the shallow-buried working face is between 1 and $3 \mathrm{~m}$ [36].

The coal in the fracture zone enters the postpeak softening stage and shows dilatancy behavior under the loading of the roof. The coal wall shows obvious transverse deformation in the horizontal direction and needs to absorb energy during the deformation process. The intact coal inside the broken zone is in the elastic deformation stage, and the excavation of the working face causes an unloading effect in the intact coal, where the horizontal stress decreases, and the energy is released in the deformation process.

In the process of mining the face, differences arise in energy conversion between the coal in the intact area and the coal in the fracture zone, which sees the energy released by the coal in the intact area being absorbed by the coal in the fracture zone. To simplify the analysis, the interface between the crushing zone and the complete zone is regarded as a stress boundary, where the work done by the stress on the coal in the crushing zone is the energy released by the coal in the complete zone. The coal in the crushing area has been completely unloaded and only bears the extrusion pressure acting on it at the stress boundary. The higher the degree of unloading of the coal in the crushing area, the greater the transverse deformation of the coal, with the extrusion pressure acting on the coal in the crushing area increasing. From the floor to the roof, the degree of disturbance of the coal seam caused by the mining increases, and the degree of unloading increases. Therefore, the extrusion pressure of the upper coal body in the fracture zone is greater. For the convenience of analysis, the boundary stress is simplified as the linear distributed load $q(x)$, as shown in Figure 2(b). The boundary between the coal body and the floor is regarded as a fixed displacement boundary. The interface between the coal seam and the roof is the stress boundary, bearing the roof load $p$ and the shear force $F$. In addition, the coal wall bears the horizontal support force provided by the support plate, which increases with the increase in the transverse deformation of the coal wall. For the convenience of analysis, the mutual support plate is equivalent to a spring with a stiffness of $k$. With the increasing transverse deformation of the coal body, the support force received by the coal body in the broken zone increases linearly. Considering the above simplification, the boundary conditions of the coal body in the crushing zone are shown in Figure 2(b). Since the primary mining height of the 12401 working face reaches $8.8 \mathrm{~m}$ and the width of the crushing zone is between 1 and $3 \mathrm{~m}$, the coal wall mechanical model is shown in Figure 2(a) which can be regarded as a beam structure under complex boundary conditions, and the coal wall failure conditions of a stope with a large mining height can be determined using this structural model.

3.2. Tensile Failure Conditions of the Coal Wall. To determine the failure conditions of the coal wall, the principle of minimum potential energy is used to find the displacement and stress of the beam structure shown in Figure 2(b). As a result of the mining, the total potential energy of the structural system shown in Figure 2(b) includes the bending deformation energy of the coal in the broken zone, the elastic potential energy stored in the mutual support plate, represented as a spring, and the external force potential energy generated by the work done by the boundary loads $q$, $p$, and $F$. Under the condition of the coal wall undergoing large deformation, its transverse deformation is greater than the 


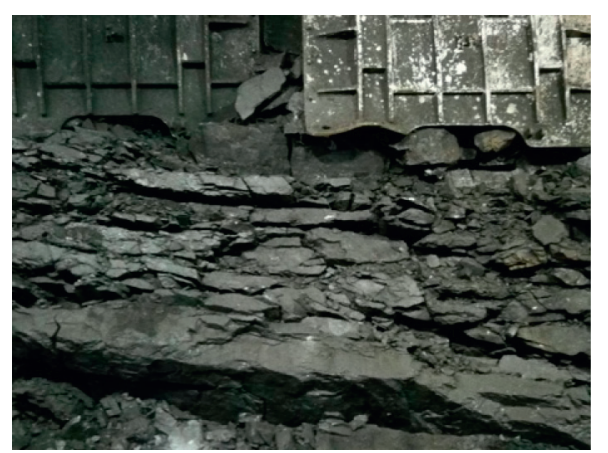

(a)

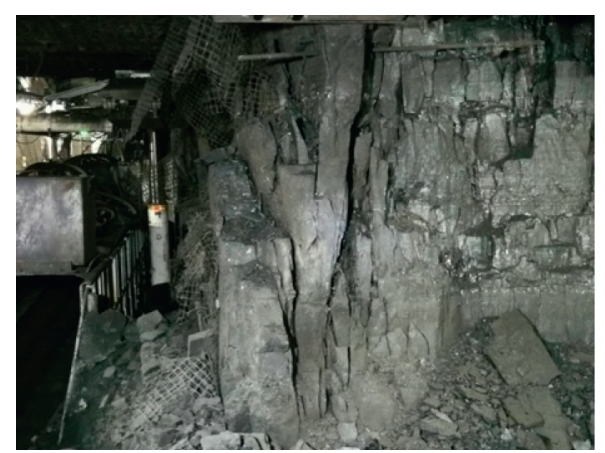

(b)

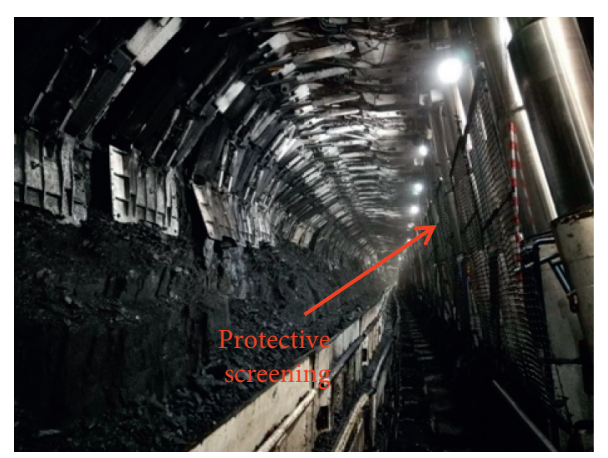

(c)

Figure 1: Examples of failure modes along the 12401 working face coal wall. (a) Horizontal crack. (b) Longitudinal crack. (c) Protective screening.

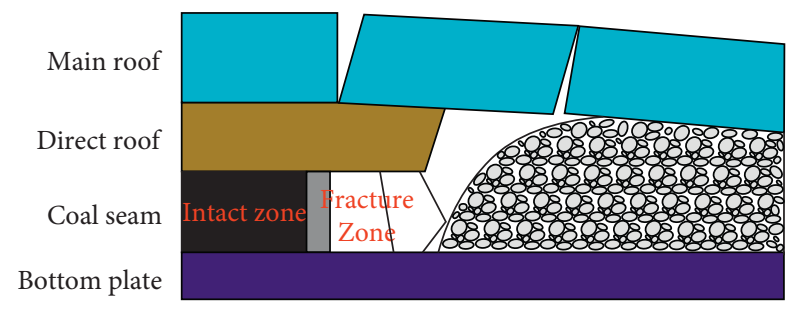

(a)

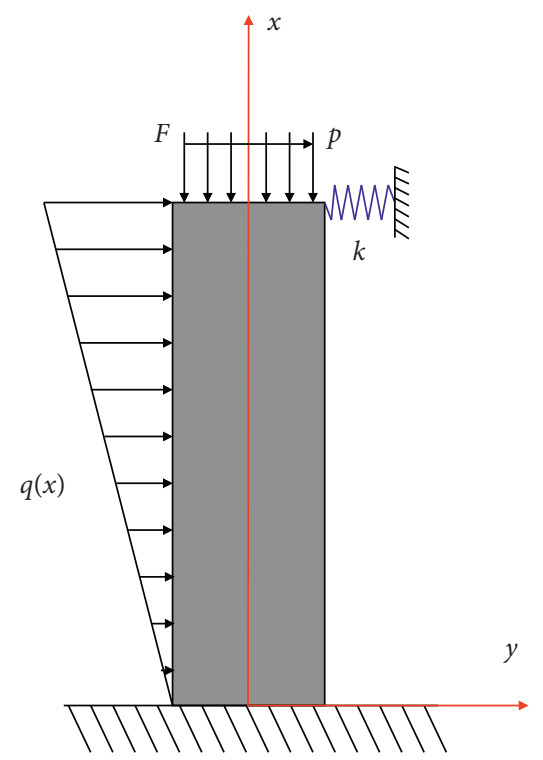

(b)

FIGURE 2: Mechanical model for a coal wall of a large height. (a) The various components around a section of high-wall coal mining. (b) Coal wall boundary conditions.

vertical deformation. Therefore, the work done by the roof load $P$ can be ignored. Hence, the total potential energy of the structure can be obtained using

$$
U(\omega)=\frac{1}{2} \int_{0}^{h} E I \omega^{\prime \prime 2} \mathrm{~d} x+\frac{1}{2} k \omega^{2}(h)-\int_{0}^{h} q(x) \omega \mathrm{d} x-F \omega(h),
$$


where $U$ is the total potential energy of the structural system $(\mathrm{J}), w$ is the lateral deformation of the coal wall $(\mathrm{m}), E$ is the elastic modulus of the coal body (GPa), $I$ is the moment of inertia of coal in the crushing zone $\left(\mathrm{m}^{3}\right)$, and $k$ is the spring stiffness (GPa).

According to the principle of minimum potential energy, the transverse displacement function for coal that minimizes the total potential energy of the system is its true displacement. Therefore, the first variation fraction of equation (1) is equal to 0 , expressed as

$$
\begin{aligned}
\delta U= & \int_{0}^{h} E I \omega^{\prime \prime} \delta \omega^{\prime \prime} \mathrm{d} x+k \omega(h) \delta \omega(h) \\
& -\int_{0}^{h} q(x) \delta \omega \mathrm{d} x-F \delta \omega(h)=0 .
\end{aligned}
$$

Integrating equation (2) by parts gives us equation (3), which after again integrating by parts gives equation (4), as shown in the following:

$$
\begin{aligned}
& \delta U=\left.E I \omega^{\prime \prime} \delta \omega^{\prime}\right|_{0} ^{h}-\int_{0}^{h} \frac{\mathrm{d}}{\mathrm{d} x}\left(E I \omega^{\prime \prime}\right) \delta \omega^{\prime} \mathrm{d} x+k \omega(h) \delta \omega(h)-\int_{0}^{h} q(x) \delta \omega \mathrm{d} x-F \delta \omega(h)=0, \\
& \delta U=\left.E I \omega^{\prime \prime} \delta \omega^{\prime}\right|_{0} ^{h}-\left.\frac{\mathrm{d}}{\mathrm{d} x}\left(E I \omega^{\prime \prime}\right) \delta \omega^{\prime}\right|_{0} ^{h}+\int_{0}^{h}\left(\frac{\mathrm{d}}{\mathrm{d} x}\left(E I \omega^{\prime \prime}\right)-q(x)\right) \delta \omega \mathrm{d} x+k \omega(h) \delta \omega(h)-F \delta \omega(h)=0 .
\end{aligned}
$$

Since the junction of the coal body and the floor in the crushing zone is a fixed displacement boundary, the displacement and rotation angle at the boundary are equal to 0 :

$$
\begin{gathered}
\left.\delta \omega\right|_{x-0}=0, \\
\left.\delta \omega^{\prime}\right|_{x-0}=0 .
\end{gathered}
$$

Substituting equation (5) into equation (4) leads to equation (6). Because of the variation in $\omega$ and $\omega^{\prime}$ values of arbitrariness and EI is always greater than zero, from equation (6), we can derive equation (7):

$$
\begin{gathered}
\delta U=\left.E I \omega^{\prime \prime} \delta \omega^{\prime}\right|_{0} ^{h}-\left[\frac{\mathrm{d}}{\mathrm{d} x}\left(E I \omega^{\prime \prime}\right)-k \omega-F\right] \\
+\int_{0}^{h}\left(\frac{\mathrm{d}}{\mathrm{d} x}\left(E I \omega^{\prime \prime}\right)-q(x)\right) \delta \omega \mathrm{d} x=0, \\
\omega^{\prime \prime}=0(x=h), \\
\frac{\mathrm{d}}{\mathrm{d} x}\left(E I \omega^{\prime \prime}\right)-k \omega+F=0(x=h), \\
\frac{\mathrm{d}^{2}}{\mathrm{~d} x^{2}}\left(E I \omega^{\prime \prime}\right)-q(x)=0(0<0<h),
\end{gathered}
$$

where for equation (7), the first part is for the fracture zone on the border with a roof of coal as the boundary condition, while the second part is for the deformed and fracture zone, where the fracture zone has a complete area at the junction of the linear load distribution $q(x)=a x$. This equation is for the surface of the fractured zone at maximum compressive stress, where the deformation differential formula can be broken down by the area of the deformation curve formula to give

$$
\begin{aligned}
w= & \frac{a}{120 E I} x^{5}-\frac{20 E I a h^{2}+3 k a h^{5}-40 E I F}{80 E I\left(3 E I+k h^{3}\right)} x^{3} \\
& +\frac{120 E I a h^{3}+7 k a h^{6}-360 E I F h}{240 E I\left(3 E I+k h^{3}\right)} x^{2} .
\end{aligned}
$$

Equation (8) is the horizontal deformation curve of the coal body in the crushing zone. Due to the deformation characteristics of coal in this zone, it is known that tensile stress must occur in the coal wall. The distribution of tensile stress in the coal in the crushing area in front of the working face can then be determined by the following equation:

$$
\begin{aligned}
\sigma_{x}= & \frac{a s}{120 I} x^{3}-\frac{60 E I a h^{2}+9 k a h^{5}-120 E I F}{80 I\left(3 E I+k h^{3}\right)} s x \\
& +\frac{120 E I a h^{3}+7 k a h^{6}-360 E I F h}{240 I\left(3 E I+k h^{3}\right)} s,
\end{aligned}
$$

where $s$ is the width of the coal wall crushing zone in front of the working face $(\mathrm{m})$.

If the maximum tensile stress determined by equation (9) reaches the tensile strength of the coal body, tensile failure will occur at the coal wall. After the coal wall becomes unstable, the elastic energy stored in the coal body is rapidly released, and part of it is converted into the initial kinetic energy of the broken coal body, resulting in the coal block ejection phenomenon, demonstrating the influence of mining height on the stability of the coal wall.

3.3. Buckling and Instability Conditions of the Coal Wall Structure. With the increase in the stope height, the bending deformation degree that the coal wall can bear before failure 
increases. At the same time, the coal wall may buckle and become unstable under the action of roof pressure. The maximum roof load that the coal structure can bear in the fracture zone can be determined by the following [36]:

$$
p_{\text {max }}=\frac{\pi^{2} E E_{t} I}{h^{2}\left(\sqrt{E}+\sqrt{E_{t}}\right)^{2}},
$$

where $P_{\max }$ is the maximum load (MPa) that can be borne by a coal body in the crushing zone, $E_{t}$ is the secant modulus (GPa) at the hardening stage of the coal body, and $E$ and $I$ are as above. When the roof load on the coal wall reaches the limit value as determined by equation (10), structural buckling instability occurs along the coal wall.

\section{Influence of Mining Height on the Stability of the Coal Wall}

4.1. Sensitivity Analysis. The elastic modulus of the coal body of 12401 working face is $2 \mathrm{GPa}$, the maximum stress value at the interface between the fracture zone and the intact area is $0.1 \mathrm{MPa}$, the rigidity of the hydraulic support is $5 \mathrm{GPa}$, the mining height is $8.8 \mathrm{~m}$, and the width of the fracture zone is $2 \mathrm{~m}$. The horizontal displacement and tensile stress distribution on the exposed face of the coal wall in the vertical direction can be obtained by substituting the above parameters into equations (8) and (9) as shown in Figure 3. As commented above, at the junction of the coal seam and the floor, the fracture zone is a fixed displacement boundary; therefore, the horizontal deformation of the coal wall is 0 . The horizontal deformation of the coal body increases slowly in the area where the coal wall is less than $2 \mathrm{~m}$ from the floor height; hence, the horizontal deformation of the coal wall will increase gradually with increasing vertical distance from the floor. At the junction of the coal wall and the roof, the horizontal deformation of the coal wall has reached $0.3 \mathrm{~m}$, while at the junction of the coal seam and the floor, the compressive stress in the coal wall reaches a maximum of $6 \mathrm{MPa}$. With increasing distance from the floor, the compressive stress in the coal wall gradually decreases. When the distance between the coal wall and the floor reaches $6 \mathrm{~m}$, the tensile stress in the coal wall reaches a peak value of about $4 \mathrm{MPa}$. After the peak point, the tensile stress in the coal wall decreases with increasing distance from the floor, eventually reaching 0 , as shown in Figure 3.

With increasing mining heights, the transverse deformation of the coal wall shows a nonlinear increase. When the height of the coal wall increases from $2.2 \mathrm{~m}$ to $11 \mathrm{~m}$, the maximum horizontal displacement of the coal wall increases from $0.0003 \mathrm{~m}$ to $0.9 \mathrm{~m}$. The maximum tensile stress in the coal wall also increases nonlinearly with increasing mining height, where increasing the height of the coal wall from $2.2 \mathrm{~m}$ to $11 \mathrm{~m}$ sees the maximum tensile stress increasing from $0.06 \mathrm{MPa}$ to $8.4 \mathrm{MPa}$. The maximum transverse deformation and the maximum tensile stress of the coal wall under different mining heights are shown in Figure 4. Given that an increasing mining height sees the deformation and tensile stress of the coal wall increasing, the probability of failure and the instability of the coal wall will also increase.

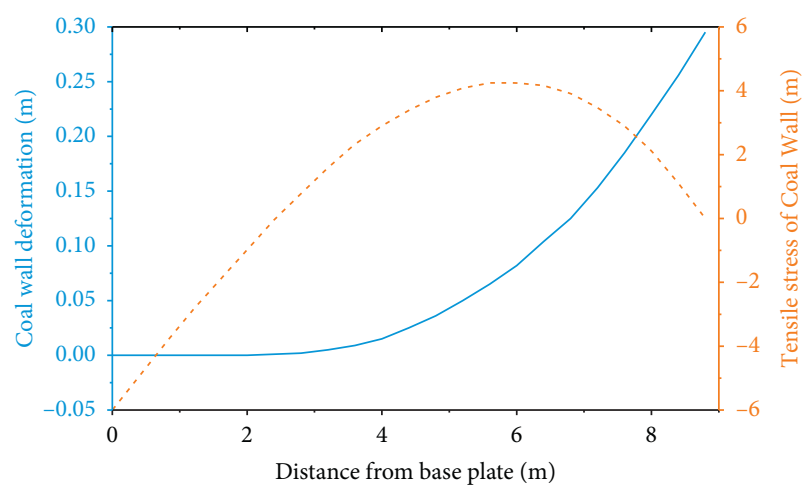

FIgURE 3: Displacement and stress distribution in the coal wall as a function of distance from the floor.

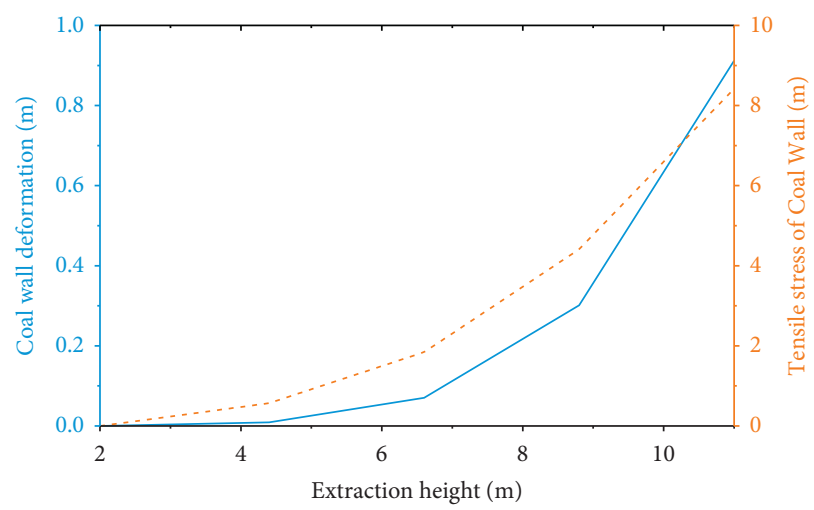

Figure 4: Influence of the mining height on the displacement and tensile stress in the coal wall.

4.2. Laboratory Verification. In order to verify the reliability of this theoretical analysis, physical simulation experiments of the stability of the coal wall as a function of mining height were designed. These experiments simulated the influence of coal wall strength, cutting height, roof load, and support stiffness on the stability of a coal wall. In this experiment, four physical models of $3 \mathrm{~m}, 5 \mathrm{~m}, 7 \mathrm{~m}$, and $9 \mathrm{~m}$ are established according to a $1: 10$ similarity ratio, as shown in Figure 5. During the experiment, the roof pressure was loaded at the rate of $0.25 \mathrm{kN} / \mathrm{s}$. At the same time, a pressure sensor was used to record the support resistance in real-time. During the roof loading, the horizontal deformation of the coal wall was measured at regular intervals using a laser rangefinder.

The resulting roof pressure and horizontal deformation of the coal wall under different mining heights are shown in Figure 6. As the height of the coal wall increases, the ultimate bearing capacity of the coal wall decreases. When the coal wall height increases from $3 \mathrm{~m}$ to $9 \mathrm{~m}$, the maximum roof pressure of the coal wall decreases from $20 \mathrm{kN}$ to $7.9 \mathrm{kN}$, and the horizontal deformation of the coal wall increases from $6 \mathrm{~mm}$ to $12 \mathrm{~mm}$. The experimental results, therefore, show that, with increasing mining height, the bearing capacity of the coal wall decreases, the deformation increases, and the stability decreases. 


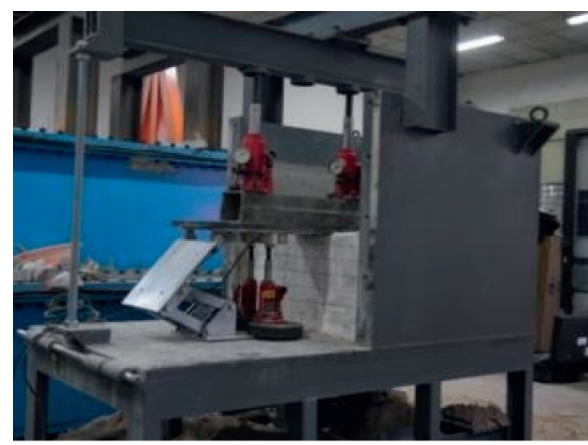

(a)

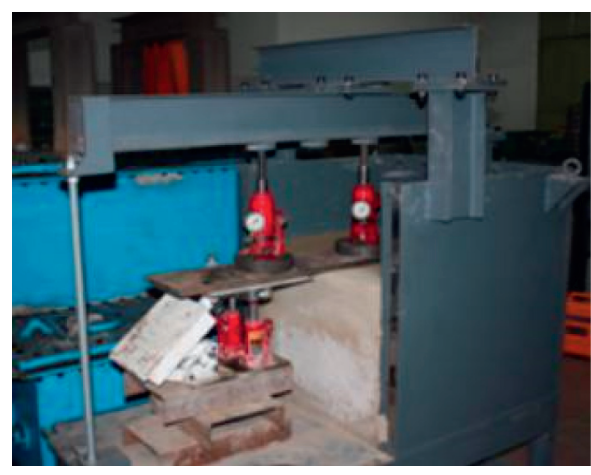

(c)

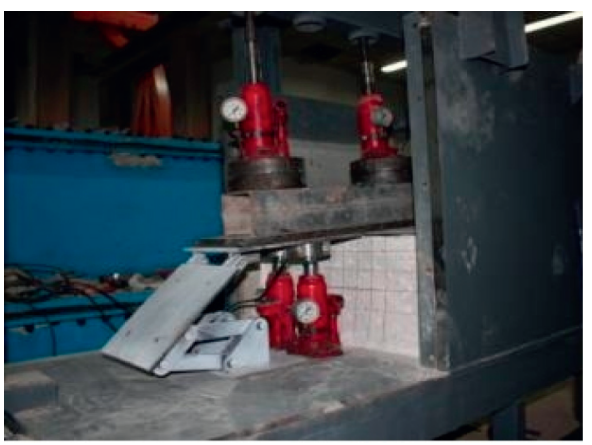

(b)

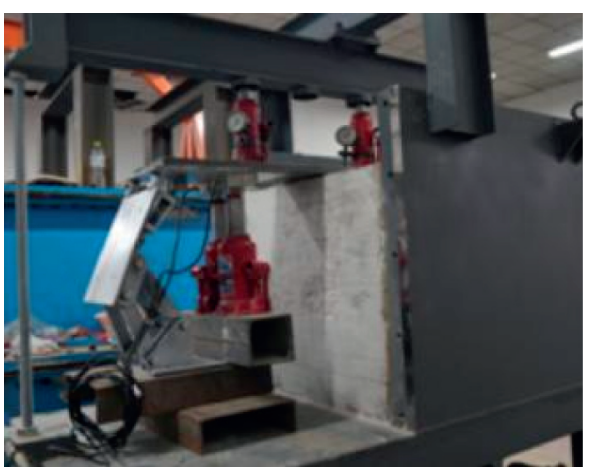

(d)

Figure 5: The model used for the physical simulations of a coal wall of different heights under load. (a) Mining height $3 \mathrm{~m}$. (b) Mining height $5 \mathrm{~m}$. (c) Mining height $7 \mathrm{~m}$. (d) Mining height $9 \mathrm{~m}$.

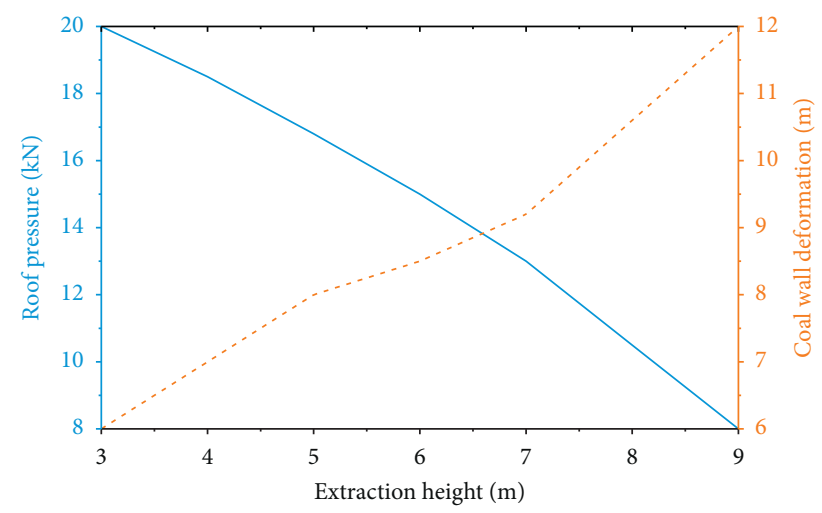

FIGURE 6: Variation in load-bearing capacity and displacement of the coal wall as a function of mining height.

The final failure form of the coal wall is shown in Figure 7. For a mining height of $3 \mathrm{~m}$, when the roof pressure reaches $20 \mathrm{kN}$, cracks and falling blocks appear in the coal wall. At this time, the coal wall appears as the upper coal slide, where the height is about $8 \mathrm{~cm}$. When the mining height increases to $5 \mathrm{~m}$, the coal wall breaks off when the roof pressure reaches $16.80 \mathrm{kN}$. Compared with the mining height of $3 \mathrm{~m}$, the area of the coal wall that breaks off increases, which is shown as upper and middle rib spalling, where the height of the rib spalling is $2.8 \mathrm{~m}$ and the depth is $5 \mathrm{~cm}$. When the mining height increases to $7 \mathrm{~m}$ and the roof pressure reaches $13 \mathrm{kN}$, the coal wall is destroyed, the extent of the rib spalling extends to the area near the floor, and the depth reaches $9.5 \mathrm{~cm}$. For a mining height of $9 \mathrm{~m}$, the whole height of the coal wall is destroyed, which is in the form of integral rib spalling, with the depth of the rib spalling increasing to $13 \mathrm{~cm}$. According to the failure forms of coal walls under different mining heights, the failure range of a coal wall and the extent of rib spalling is therefore seen to increase with increasing mining heights.

\section{Stability Control of Coal Wall in Shallow and Large Mining Height Stope}

With regard to the mining practices undertaken at the 12401 working face, considering the mechanism of coal wall lamping and the occurrence of high mine pressure arising from an $8.8 \mathrm{~m}$ working face, the coal wall stability control method of superlarge space stopes is proposed to control the coal wall stability during mining operations. From equations (8) and (9), the relationships between the horizontal deformation of the coal wall, the tensile stress, and the maximum compressive stress $q$ at the interface of the intactfractured zone can be obtained, as shown in Figure 8.

When the maximum compressive stress at the interface is $0.1 \mathrm{MPa}$, the maximum horizontal deformation and the maximum tensile stress are $0.3 \mathrm{~m}$ and $4.3 \mathrm{MPa}$, respectively. We also see from Figure 8 that the maximum horizontal deformation and the maximum tensile stress in the coal wall increase linearly. When the value of the stress increases to $0.5 \mathrm{MPa}$, the maximum horizontal deformation and the maximum tensile stress in the coal wall increase to $1.5 \mathrm{~m}$ and 


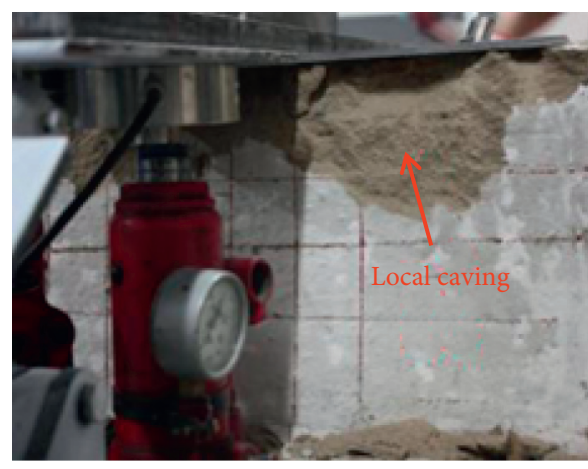

(a)

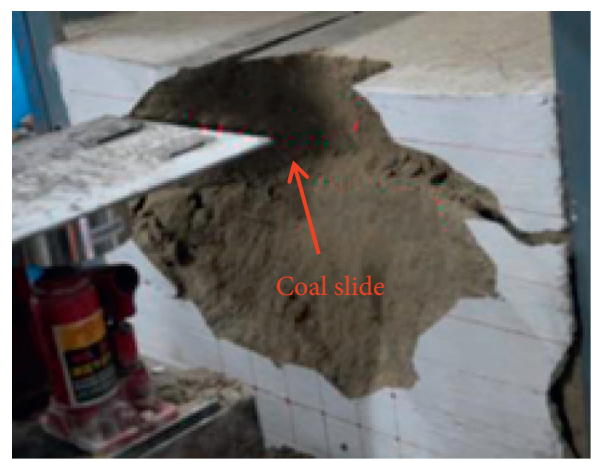

(c)

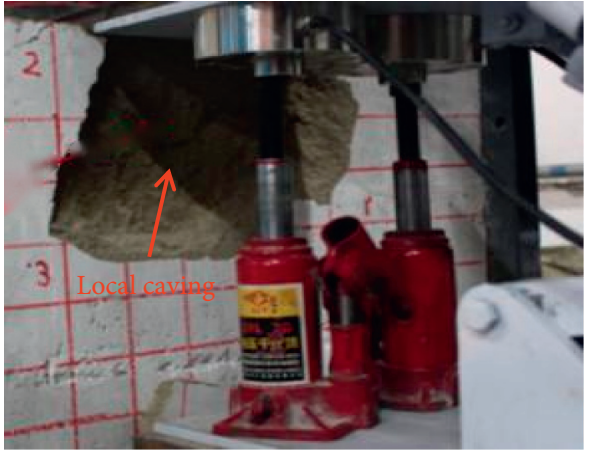

(b)

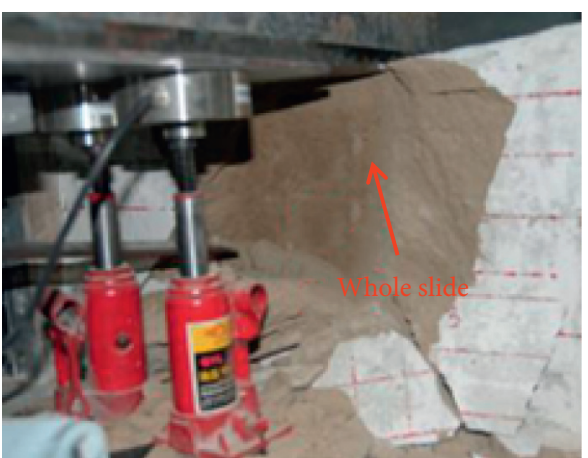

(d)

FIGURE 7: Variation in the failure modes of a simulated coal wall as a function of simulated mining height. (a) Mining height $3 \mathrm{~m}$. (b) Mining height $5 \mathrm{~m}$. (c) Mining height $7 \mathrm{~m}$. (d) Mining height $9 \mathrm{~m}$.

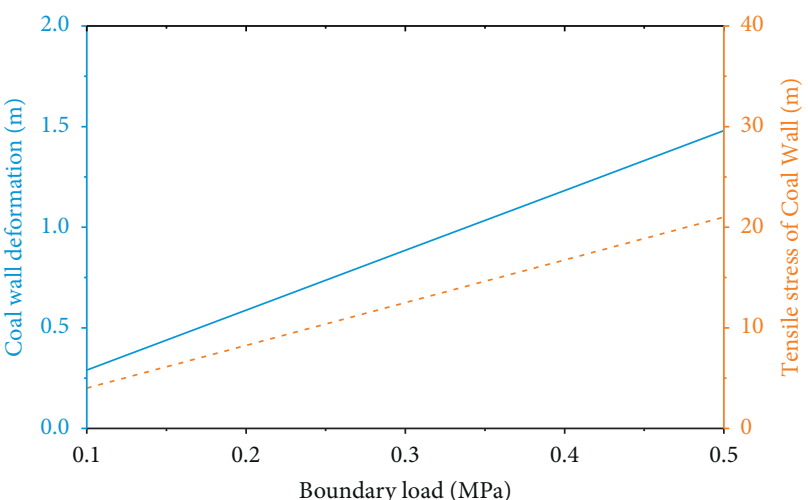

FIGURE 8: Influence of the load $q$ (Figure 2) on the stability of the coal wall.

21.5 $\mathrm{MPa}$, respectively. The above changes, therefore, indicate that the stability of the deteriorated coal wall increases with the compressive stress level at the interface between the intact zone and the fracture zone in front of the working face.

According to studies of coal wall failure mechanisms, an analytical mechanical model of coal wall stability that considers support stiffness and support structure has been established. The horizontal deformation and tensile stress of a coal wall increase linearly with the compressive stress at the interface between the intact and broken coal body in front of the working face, leading to the risk of coal wall failure increasing. Various measures, such as increasing the initial support force, maximum support force, support stiffness, and support plate stiffness of the hydraulic support, are put forward to improve the stability of the high-wall coal walls for the $8.8 \mathrm{~m}$ large-height working face, to reduce the crack development degree of the coal wall, and to increase the flatness. Employing a coal stope wall-basic roof-direct roofframe mechanical balance system and employing the energy method to determine the coal wall stress and support resistance stiffness of the components of the system, we can see the coal wall pressure increases with an increase in the complete rigidity of the coal. This destroys the immediate roof and sees the support stiffness being reduced, with the development of support resistance tending towards the opposite.

The support resistance provided by a support panel is opposite to the compressive stress acting on the interface. The stability of the coal wall can be improved by increasing the initial support force, support height, stiffness, and maximum support resistance of the support panel. To this end, the following measures are taken to control the stability of the coal wall for the 12401 working face: (1) To improve the supporting force of the protecting board, the horizontal thrust of the protecting board is increased, immediately opening the protecting board after the unit cuts the coal and moving the frame before the unit cuts the coal. Only then will the protecting board be retracted ahead of time in the shearer 1 2 frames, causing the working face coal wall to be always under the support of the protecting board. This 


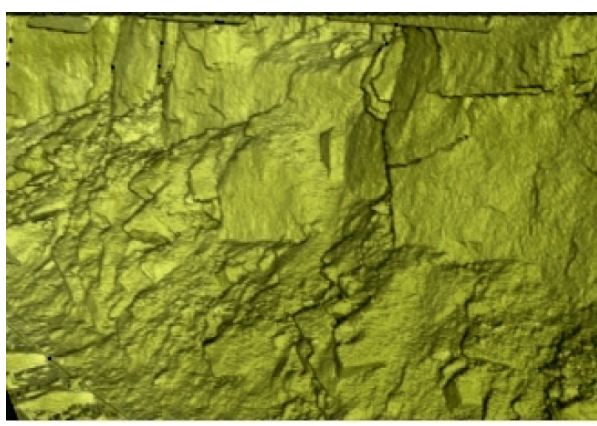

(a)



(b)

Figure 9: Comparison of failure modes of the 12401 coal wall. (a) Before increasing the strength of the shield. (b) After strengthening the strength of the shield.

provides restraint when exposing the coal body, causing the coal body cracks to still be under the three-dimensional compression conditions, preventing big block coal occurrence, while also allowing the coal machine to cut the coal in the crack development area. (2) Increasing the guard height: when the coal wall is seriously damaged, the protective board can be opened manually to move the first protective board closer to the coal wall or the roof and the second protective board closer to the coal wall to reduce the recovery time of the expansion beam and the protective board when the shearer cuts the coal, hence increasing the supporting time of the protective board at the roof and the coal wall. (3) The structural optimization design of the hydraulic support: according to the intensifying mechanism of rib spalling in large mining height working faces, increasing the support force of the front end of the roof beam is one of the most effective measures for controlling rib spalling and caving at the working face. Large mining height working face hydraulic support must include a top beam design for the overall top beam plus an expansion beam structure. The expansion beam front-hinged support structure involves a three-level mechanism: the first and third levels support the plate using a small four-link structure, which can turn $180^{\circ}$, with the second-level support plate and the first-level support plate being kept level, while the third-level support plate is folded back. (4) Strengthening the management of the hydraulic system by increasing the actual support force and working resistance of the support: this involves increasing the hydraulic pressure of the pumping station as much as possible, using the initial support force retaining valve to increase the actual support force, and improving the reliability of the protecting board. (5) Since the horizontal deformation and tensile stress of the coal wall are linearly related to the compressive stress at the interface between the coal body integrity area and the fracture zone in front of the working face, the pressure situation of the working face should be monitored to determine the advancing speed of the working face to reduce the exposure time of the coal wall and to reduce the degree of coal wall lamping.

During the initial propulsive process of working face 12401, the destruction of the coal wall is frequent, which seriously restricts the production capacity of the fully mechanized working face with a large mining height, while the unevenness of the coal wall reduces the management level of the working face. In order to improve the stability of the coal wall of the 12401 working face, considering the above measures, the initial supporting force of the $8.8 \mathrm{~m}$ hydraulic support backing board was increased, and the three-level backing board was adopted to increase the height of the backing board. After taking the above measures, the stability of the coal wall was improved, with the degree of fracture development on the coal wall decreasing and the flatness of the coal wall increasing, as shown in Figure 9(b). The increase in the stability and flatness of the coal wall reduces its influence on the shearer, improves the shearer's cutting efficiency, and enhances the advancing speed of the working face.

\section{Conclusions}

(1) Under the condition of shallow burial, the damage range of a coal body in front of a working face is small, with the dynamic damage taking place in the middle and upper parts of the coal wall under the influence of mining. The initial starting speed of the broken coal body is associated with the ejection injury phenomenon. The mechanical model of a coal wall for a shallow mining face with a large mining height has been established, and the mechanical conditions of tensile failure and structural buckling instability of a coal wall are obtained.

(2) The lower part of the coal wall is restrained by the floor; hence, the horizontal deformation is close to 0 , and there is no tensile stress distribution in the coal body. The tensile stress first increases and then decreases to 0 with increasing vertical distance from the floor. Therefore, the middle and upper parts of the measured coal wall are the most seriously damaged.

(3) A series of physical simulation experiments examining the stability of a coal wall under different mining heights were designed. The height of the coal wall was increased from 3 to $9 \mathrm{~m}$, which saw the horizontal deformation of the coal wall increasing from $6 \mathrm{~mm}$ to $12 \mathrm{~mm}$, the ultimate bearing capacity decreasing from $20 \mathrm{kN}$ to $7.9 \mathrm{kN}$, the height of the rib 
wall increasing from $8 \mathrm{~cm}$ to $90 \mathrm{~cm}$, and the depth of the lamella increasing from $3 \mathrm{~cm}$ to $13 \mathrm{~cm}$.

(4) The horizontal deformation and tensile stress of the coal wall increases linearly with compressive stress at the interface between the intact zone and the broken zone in front of the working face. Measures such as increasing the initial supporting force, the maximum supporting force, and the stiffness of the support plate of the hydraulic support are put forward to improve the stability of the high wall of the coal face with an $8.8 \mathrm{~m}$ high mining height. In doing so, this reduces the degree of the development of the cracks in the coal wall and increases the flatness.

\section{Data Availability}

The data used to support the findings of this study are included within the article.

\section{Conflicts of Interest}

The authors declare that there are no conflicts of interest regarding the publication of this study.

\section{Acknowledgments}

This study was supported by the State Key Research Development Program of China (Grant no. 2017YFC0804310).

\section{References}

[1] J. C. Wang, J. W. Zhang, and Z. H. Wang, Basic Theory and Application of Sublevel Caving Mining, Beijing Science Press, Beijing, China, 2018.

[2] L. Qiu, D. Song, Z. Li, B. Liu, and J. Liu, "Research on AE and EMR response law of the driving face passing through the fault," Safety Science, vol. 117, no. 17, pp. 184-193, 2019.

[3] X. W. Yin, "Cutting block structure model of overburden with shallow buried coal seam and ultra-large mining height working face," Journal of China Coal Society, vol. 44, no. 7, pp. 1961-1970, 2019.

[4] Y. J. Liu, Q. Qi, and A. H. Wang, "Influence of valleys terrain on pressure of fully mechanized working faces in shallow coal seams," Shock and Vibration, vol. 2021, Article ID 8880041, 11 pages, 2021.

[5] S. Mahdi and C. Li, "Analytical approaches for studying the stability of laminated roof strata," International Journal of Rock Mechanics and Mining Sciences, vol. 79, no. 10, pp. 99-108, 2015.

[6] A. J. Das, P. K. Mandal, R. Bhattacharjee, S. Tiwari, A. Kushwaha, and L. B. Roy, "Evaluation of stability of underground workings for exploitation of an inclined coal seam by the ubiquitous joint model," International Journal of Rock Mechanics and Mining Sciences, vol. 93, no. 3, pp. 101-114, 2017.

[7] X. W. Yin, S. H. Yan, and Y. An, "Characters of the rib spalling in fully mechanized caving face with great mining height," Journal of Mining \& Safety Engineering, vol. 25, no. 2, pp. 222-225, 2008.

[8] H. Wang, X. Fang, Y. Li, Z. Zheng, and J. Shen, "Research and application of the underground fire detection technology based on multi-dimensional data fusion," Tunnelling and
Underground Space Technology, vol. 109, no. 109, Article ID 103753, 2021.

[9] S. L. Yang, B. Zhao, and L. H. Li, "Coal wall failure mechanism of longwall working face with false dip in steep coal seam," Journal of China Coal Society, vol. 44, no. 2, pp. 367-376, 2019.

[10] P. R. Sheorey, J. P. Loui, K. B. Singh, and S. K. Singh, "Ground subsidence observations and a modified influence function method for complete subsidence prediction," International Journal of Rock Mechanics and Mining Sciences, vol. 37, no. 5, pp. 801-818, 2000.

[11] L. J. Donnelly, H. De La Cruz, I. Asmar et al., "The monitoring and prediction of mining subsidence in the amaga, angelopolis, venecia and bolombolo regions, antioquia, Colombia," Engineering Geology, vol. 59, no. 1, pp. 103-114, 2001.

[12] J. C. Wang, "Mechanism of the rib spalling and the controlling in the very soft coal seam," Journal of China Coal Society, vol. 32, no. 8, pp. 785-788, 2007.

[13] Y. Yuan, S. H. Tu, X. T. Ma, L. L. Sun, and Q. S. Bai, "Coal wall stability of fully mechanized working face with great mining height in "three soft" coal seam and its control technology," Journal of Mining \& Safety Engineering, vol. 29, no. 1, pp. 21-25, 2012.

[14] H. Wang, X. Fang, F. Du et al., "Three-dimensional distribution and oxidation degree analysis of coal gangue dump fire area: a case study," The Science of the Total Environment, vol. 772, Article ID 145606, 2021.

[15] Z. H. Wang, J. C. Wang, Y. Yang et al., "Mechanical relation between support stiffness and longwall face stability within fully-mechanized mining faces," Journal of China University of Mining \& Technology, vol. 48, no. 2, pp. 258-267, 2019.

[16] X. Q. Fang, J. He, and H. C. Li, "A study of the rib fall mechanism in soft coal and its control at a fully-mechanized top-coal caving face," Journal of China University of Mining \& Technology, vol. 38, no. 5, pp. 640-644, 2009.

[17] F. Du, K. Wang, X. Zhang, C. Xin, L. Shu, and G. Wang, "Experimental study of coal-gas outburst: insights from coalrock structure, gas pressure and adsorptivity," Natural Resources Research, vol. 29, no. 6, pp. 2481-2493, 2020.

[18] X. Ding, X.-c. Xiao, D. Wu, and X.-f. Lv, "Mechanical properties and charge signal characteristics in coal material failure under different loading paths," International Journal of Coal Science \& Technology, vol. 6, no. 1, pp. 138-149, 2019.

[19] J. C. Wang, Y. C. Yang, and D. Z. Kong, "Failure mechanism and grouting reinforcement technique of large mining height coal wall in thick coal seam with dirt band during topple mining," Journal of Mining \& Safety Engineering, vol. 31, no. 6, pp. 831-837, 2014.

[20] S. L. Yang and D. Z. Kong, "Flexible reinforcement mechanism and its application in the control of spalling at large mining height coal face," Journal of China Coal Society, vol. 40, no. 6, pp. 1361-1367, 2015.

[21] G. F. Song, S. L. Yang, and Z. H. Wang, "Longwall face stability analysis using Ritz method and its 3D physical modelling study," Journal of China Coal Society, vol. 43, no. 8, pp. 2162-2172, 2018.

[22] S. L. Yang and Y. Yang, "Experimental research on optimization of face injection and flexible bolting technology," Journal of China Coal Society, vol. 44, 2019.

[23] S. K. Singh, H. Agrawal, A. P. Singh et al., "A way forward for safe coal extraction in India," International Journal of Mining Science and Technology, vol. 27, 2017.

[24] H. Basarir, I. Ferid Oge, and O. Aydin, "Prediction of the stresses around main and tail gates during top coal caving by 
3D numerical analysis," International Journal of Rock Mechanics and Mining Sciences, vol. 76, pp. 88-97, 2015.

[25] Z. H. Wang, J. H. Yang, and H. Meng, "Mechanism and controlling technology of rib spalling in mining face with large cutting height passing through fault," Journal of China Coal Society, vol. 40, no. 1, pp. 42-49, 2015.

[26] J. C. Wang, Z. H. Wang, and D. Z. Kong, "Failure and prevention mechanism of coal wall in hard coal seam," Journal of China Coal Society, vol. 40, no. 10, pp. 2243-2250, 2015.

[27] L. Qiu, Z. Liu, E. Wang, X. He, J. Feng, and B. Li, "Earlywarning of rock burst in coal mine by low-frequency electromagnetic radiation," Engineering Geology, vol. 279, no. 279, Article ID 105755, 2020.

[28] D. Xue, J. Zhou, Y. Liu, and L. Gao, "On the excavationinduced stress drop in damaged coal considering a coupled yield and failure criterion," International Journal of Coal Science \& Technology, vol. 7, no. 1, pp. 58-67, 2020.

[29] L. Dou, K. Yang, and X. Chi, "Fracture behavior and acoustic emission characteristics of sandstone samples with inclined precracks," International Journal of Coal Science \& Technology, vol. 8, no. 1, pp. 77-87, 2021.

[30] J. C. Wang, L. Wang, and Y. Guo, "Determining the support capacity based on roof and coal wall control," Journal of China Coal Society, vol. 39, no. 8, pp. 1619-1624, 2014.

[31] D. Z. Kong, S. L. Yang, L. Gao, and Z. Q. Ma, "Determination of support capacity based on coal face stability control," Journal of China Coal Society, vol. 42, no. 3, pp. 590-596, 2017.

[32] F. F. Wu, Study on Law and Control of Overburden Rock Failure and Instability in Fully Mechanized Mining with Large Mining Height in Thick Coal Seam, China University of Mining and Technology, Xuzhou, China, 2014.

[33] P. S. Zhang, S. A. Xu, L. Q. Guo et al., "Progress and prospect of monitoring technology for stope surrounding rock deformation and failure," Coal Science and Technology, vol. 48, no. 3, pp. 14-48, 2020.

[34] Y. Zhang, "Study on surrounding rock control of stope under goaf under complex surface," Coal Mine Modernization, vol. 2020, no. 2, pp. 24-26, 2020.

[35] X. F. Wu, "Study on surrounding rock control technology of roadway in mining area under the influence of mining in close distance coal seam," Coal Mine Modernization, vol. 2020, no. 1, pp. 39-41+44, 2020.

[36] M. X. Chen, Elast-Plastic Mechanics, Beijing Science Press, Beijing, China, 2006. 